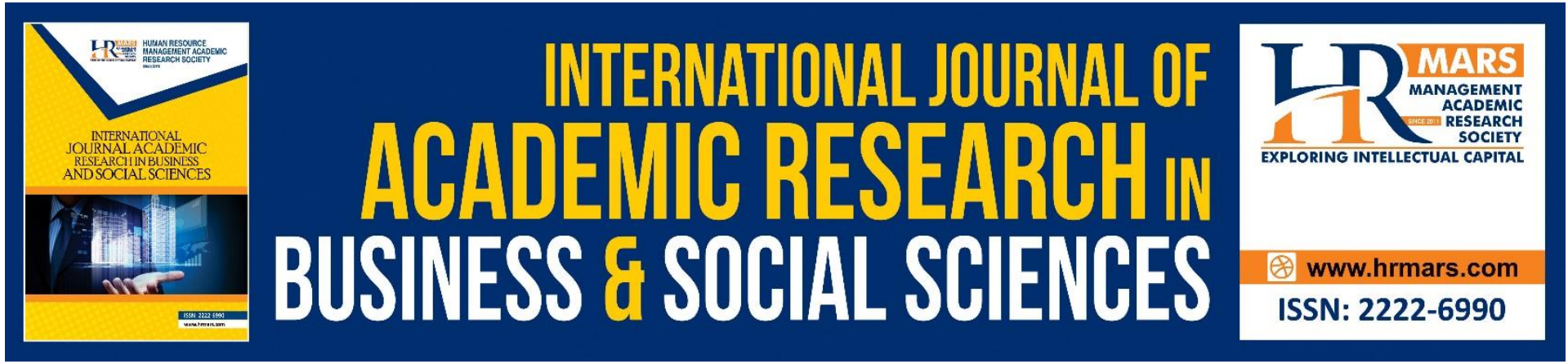

\title{
Clay as an Alternative Matrix for Printmaking
}

\section{KusfaizluHakim Kusmawi \& Wan Samiati Andriana WMD}

To Link this Article: http://dx.doi.org/10.6007/IJARBSS/v11-i6/10341

DOI:10.6007/IJARBSS/v11-i6/10341

Received: 25 April 2021, Revised: 28 May 2021, Accepted: 12 June 2021

Published Online: 28 June 2021

In-Text Citation: (Kusmawi \& WMD, 2013)

To Cite this Article: Kusmawi, K., \& WMD, W. S. A. (2013). Clay as an Alternative Matrix for Printmaking. International Journal of Academic Research in Business and Social Sciences, 11(6), 1318-1326.

Copyright: (c) 2021 The Author(s)

Published by Human Resource Management Academic Research Society (www.hrmars.com)

This article is published under the Creative Commons Attribution (CC BY 4.0) license. Anyone may reproduce, distribute, translate and create derivative works of this article (for both commercial and non-commercial purposes), subject to full attribution to the original publication and authors. The full terms of this license may be seen

at: http://creativecommons.org/licences/by/4.0/legalcode

Vol. 11, No. 6, 2021, Pg. 1318 - 1326

http://hrmars.com/index.php/pages/detail/IJARBSS

JOURNAL HOMEPAGE

Full Terms \& Conditions of access and use can be found at http://hrmars.com/index.php/pages/detail/publication-ethics 


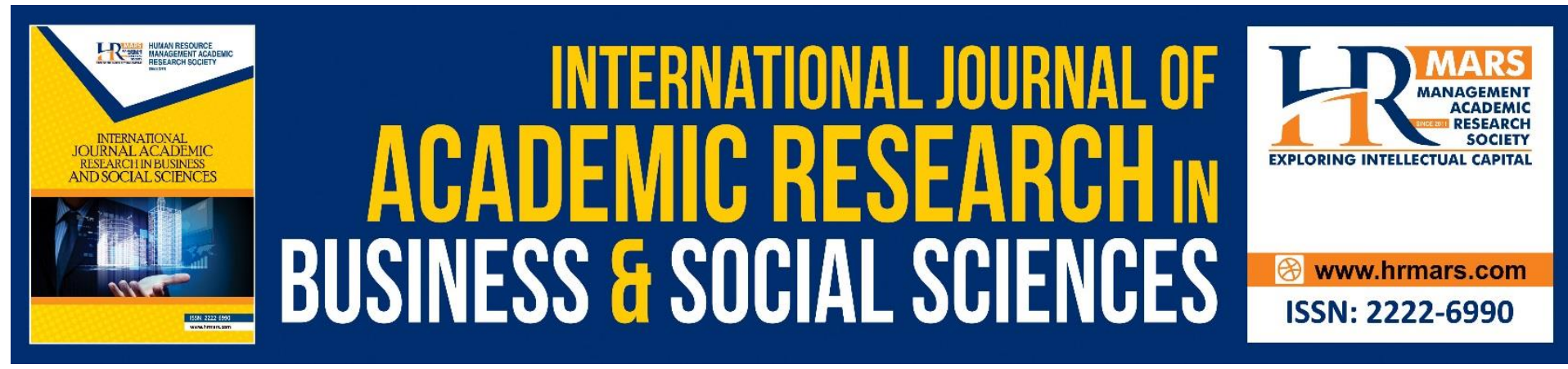

\title{
Clay as an Alternative Matrix for Printmaking
}

\author{
KusfaizluHakim Kusmawi \& Wan Samiati Andriana WMD \\ Department of Fine Arts, Universiti Teknologi MARA, Shah Alam, Selangor, Malaysia \\ Email: kusfaizlulhakim@gmail.com
}

\begin{abstract}
This paper will present and discuss creative practice-base; the alternative approach using clays as a matrix for printmaking. The study replicated Lyon's framework of clay matrix. This research shows the sample of an experiment using multiple combinations of mediums that is suitable for this type of printmaking. The experiment concludes non-woven paper is the best use for clay print. It also opens the possibility of the idea that non-woven materials can also be made of clay print such as kitchen towels, polypropylene and table linen. Clay print is full of surprises and charms, it is also an example of how this technology will integrate and benefit both Fine Arts and Ceramic fields.
\end{abstract}

Keywords: Alternative, Clay, Matrix, Printmaking

\section{Introduction}

Printmaking is the method of creating artwork utilizing a printing technique; that is, the method of transferring an image from a matrix surface to a sheet of paper, or another medium's surface. Melot (1988) stated "Print-making components; matrix or a model for displaying the material and the image; a plate or block is a must in the process of making artwork. The art of printing has been practiced for the purpose of duplicate script and manuscript. The catch of this approach is that it will manufacture and sell bulk products on a wide scale. "The calculation must be precise for the board to produce mass production. Matrix is a block or scheme that has the same measurement quantity as long as the block remains true to the matrix according to Oxford (2016). This principle applies to printmaking techniques ranging from relief, intaglio, silkscreen and lithography. However, there's a type of print discipline called monotype; Abdullah (2020) explains it is a discipline that is achieved by making print but is not treated as a "copy" but rather as an "original.". Mono-print feathered the gap between other disciplines, the sky's the limit as monotype able to adapt with any medium.

Across the globe, Mitch Lyons, an American ceramic artist has found a creative way of mono-printing. He noticed that the concept of clay was acceptable for printing. This distinctive feature is a significant element that is highlighted in this research. Melot (1988) and Waever (1989) proclaimed that clay has a plasticity characteristic value; it can easily be modelled, formed and built by combining it with the concept matrix that can create a special style of art. Lyons saw this as a chance to mix this style of conventional art with something modern. College of the Arts (2016) claims the artists follow printmaking in new, philosophical and imaginative ways, based on the printmaking fundamentals. 
"I'm still intrigued by printers, the way they work and the artwork makes me wonder what if I could achieve the attitude of printers in the field of ceramics" Lyons (2017).

In comparison to painting and sculpture, clay print has its qualities that cross both printmaking and ceramic practice. He describes that by using the clay slab to be the base and the paint slips to substitute the ink to produce images, the clay may be transferred to another surface. According to Sill (1981) and Lucas (2015) the transition takes place because of the static charge between the clay and the paper. The clay matrix builds up the positive charge and draws the colour slides to the negative charge of the unwoven surface and absorbs the "dust" like a magnet.

Based on current and previous studies relevant to the alternative matrix, clay printing requires more comprehensive knowledge and introduction to Malaysia, on other hand, there are not many studies on clay print in Malaysia. The objective of this research is to replicate Lyons's framework of clay print. This research will benefit different groups within the art society such as curators, artists, designers, and art educators in Malaysia, who have been able to use clay as matrix.

\section{Method}

The purpose of this research is to replicate Lyons's clay print matrix and do an observation the leaves marks with different medium and papers The matrix will be examined using a water-based medium: gauche, watercolour, colour slip, pastel powder and pencil, and various paper textures (woven and nonwoven).

The construction for the matrix is made from a plywood $36 \mathrm{~cm} \times 32.9 \mathrm{~cm}$ (as base), two $30.2 \mathrm{~cm} \times 2.9 \mathrm{~cm} \times 0.5$ and two $32.9 \mathrm{~cm} \times 2.9 \mathrm{~cm} \times 05 \mathrm{~cm}$ wood (as a frame). The skeleton of the matrix has a slot space in the middle for the clay slab to be inserted later. Fig .1. Shows the diagram of how the skeleton is made. The frame and the base were fused together with wood glue and nails and let it sit for 12 hours. After the drying process, a layer plastic sheet was put inside the slot for protecting the wood surface from getting wet. A $1.5 \mathrm{~kg}$ of earthenware clay was put inside the block with a slabbing technique. Sprayed a few veils of a mist of water onto the slab and covered with a plastic sheet to keep the clay moist.

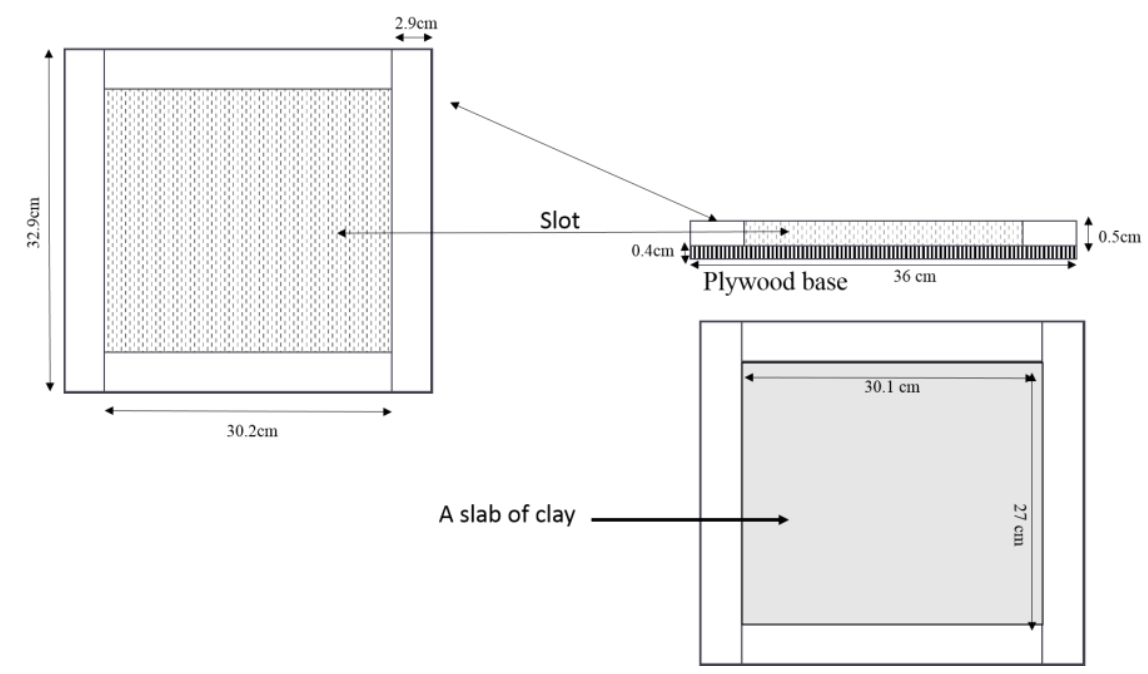

Figure.1. Fabricating the matrix 
Clay print is taking influence from traditional print technique; woodcut, linocut, engraving and it is mostly inspired by Planography but with a twist of monoprint. Print on clay is a form of art that complements the unique features of printmaking and ceramic art. The experiment runs with the method suggested by Lyons. In the test, the researcher used earthenware clay because it is much more commonly used both in the education field and industry than porcelain clay. Some additional material and medium were added by the researcher. The material is additional water base mediums' gouache, watercolour, colour slip, pastel powder and ink.

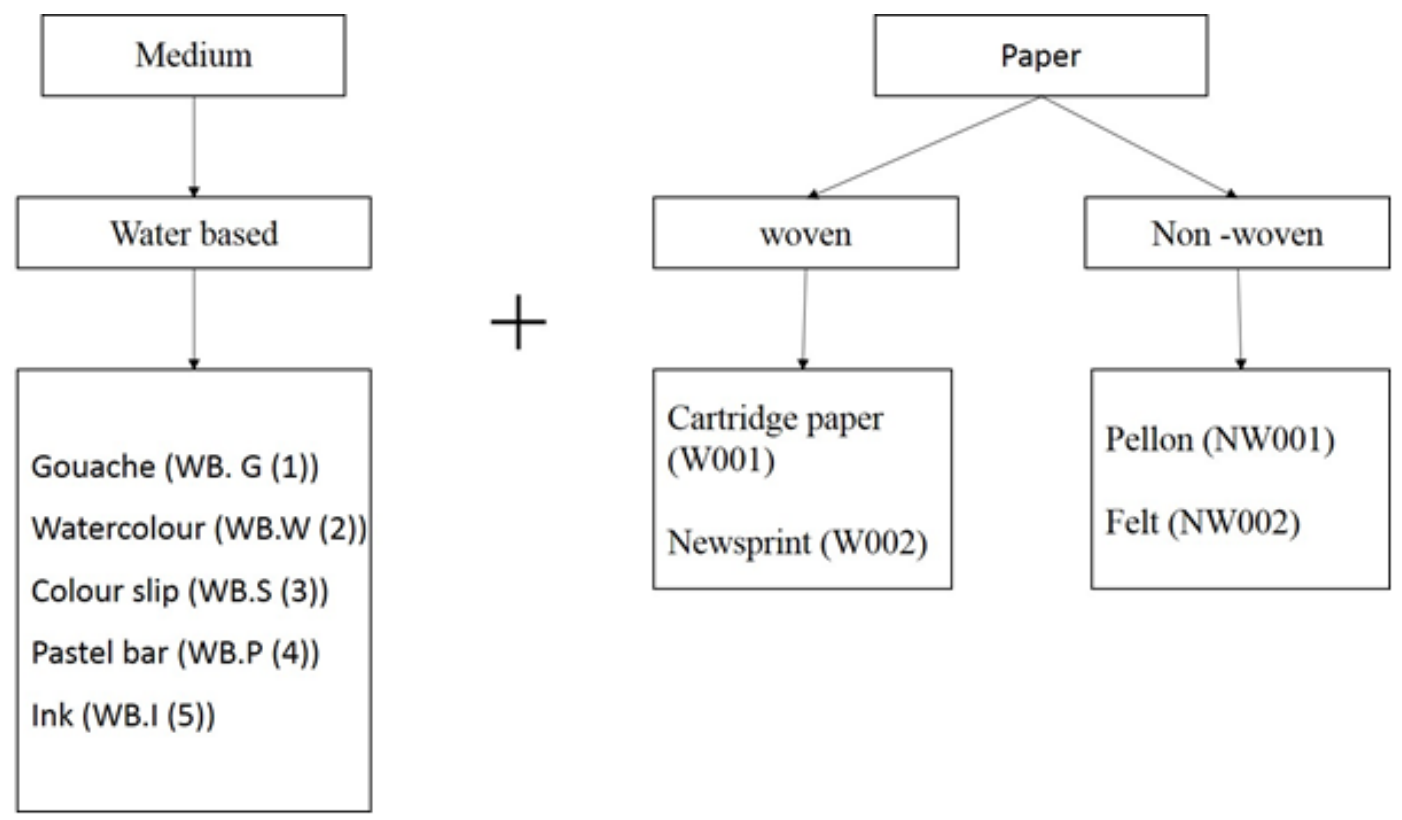

Figure 2: medium and surface selection

Figure 2 shows the chosen medium and surface. The reason behind the selection is the familiarity of a medium utilised around the studio, with the additional materials suggested by Lyons to include Pellon and colour slip (liquid clay mixed with paint pigment). The medium was chosen to be water-base because the clay is not suitable with oil base medium. Then, the materials were labelled according to types as illustrated in figure 2. 


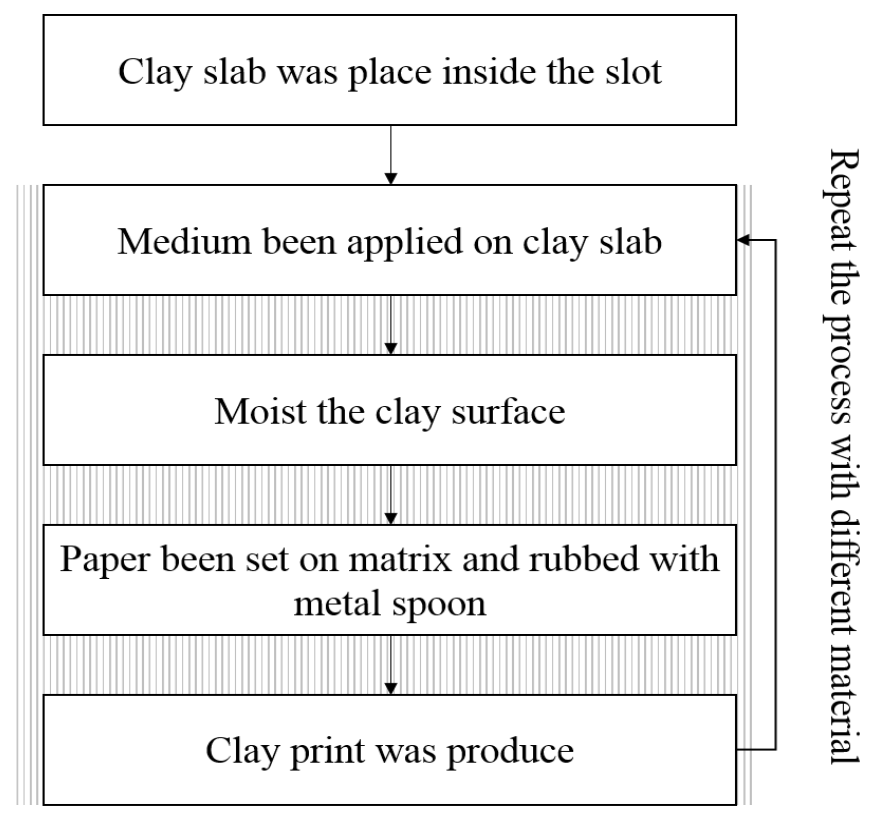

Figure 3: Clay print steps

After the material was selected, the matrix and the material were put in an experiment. The step is the base of Lyons's framework of producing clay print. Fig 3 exhibits the step used in the process. In this process, there are multiple media being tested, while in Lyons original process only used colour slips.

The first step is to place the clay slab into the slot, smooth the surface from lumps and debris. Then, apply a water-base medium onto the clay matrix. Tools such as brush may be used in this step to help with the imagery construct. After the illustration is completed, spray a mist of water using a bottle to the matrix. The matrix needs to be moist, not wet. Let it rest for two minutes before using the matrix. When the matrix is ready to be used, place the paper onto the matrix and rub the back with a metal spoon. During this process, electrostatics pulls the medium from the matrix to the surface of the paper. Thus, the transferring process has occurred. After the transferring process, the paper can simply be hand pulled hence the transferring process is completed and the image is observed.

Fig 4 showed a sample of steps being executed using Lyons's framework. It starts with the clay slab placed in the slot and proceeds to apply medium onto the matrix. Then a spray bottle was used to make a wisp of mist on the surface, after a decent amount of time the transferring process from the matrix to paper started. The rubbing process was done in a circular motion to get the full image transfer to the paper and after that, on the hand pull process the paper was lifted carefully. The result was a mirror image from the matrix. The process is repeated with different mediums and paper to observe the different results that occur. 

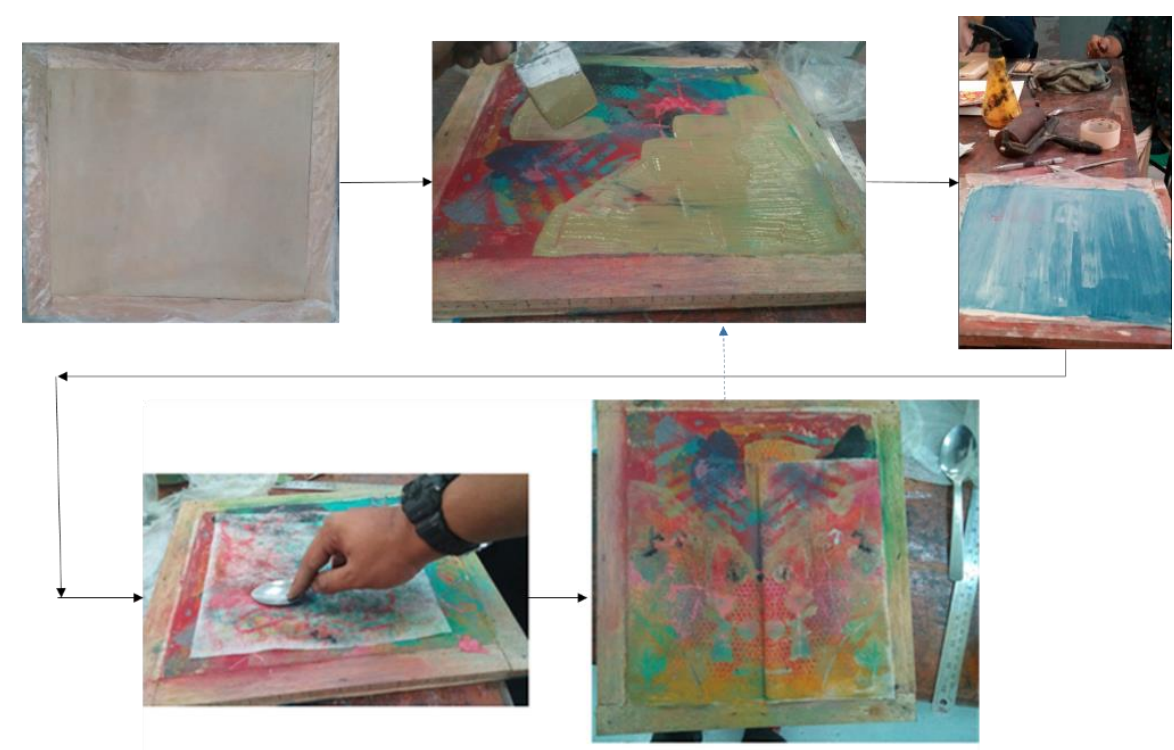

Figure 4: Execution

\section{Finding}

The experiment was done in the Printmaking studio, UiTM Shah Alam. The matrix follows the process as stated in figure 3 . The earthen clay slab was placed inside the slot and mediums were applied onto the matrix. Fig 5 exhibits the five types of the medium; $5 . a$ is (WB. $G(1)$ ), 5.b is (WB. W(2)), 5.c is (WB. S(3)), 5 d is (WB. P (4)) and 5e is (WB. I (5)). The medium clearly has different opacity for instance fig 5.b and fig 5.e display the effects produced on the matrix. (WB. I (5)) and (WB. W (2)) is more transparent than (WB. G (1)), (WB. S (3)) and (WB. P (4)).

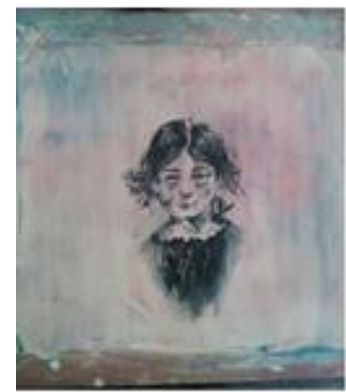

a

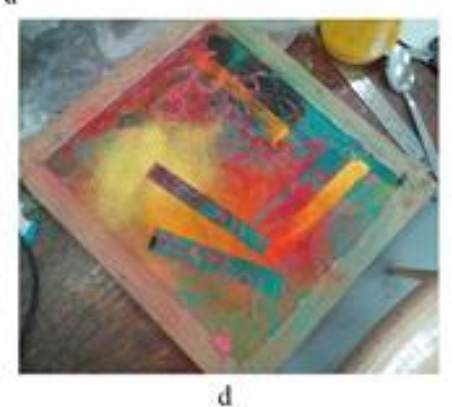

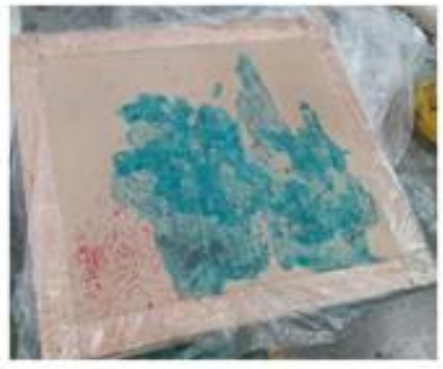

b

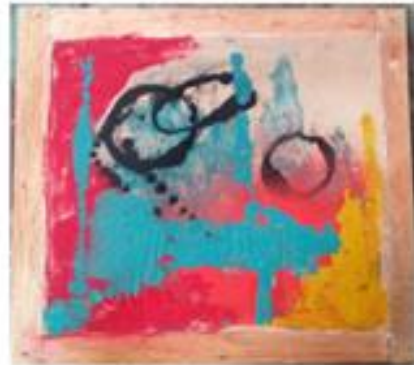

c

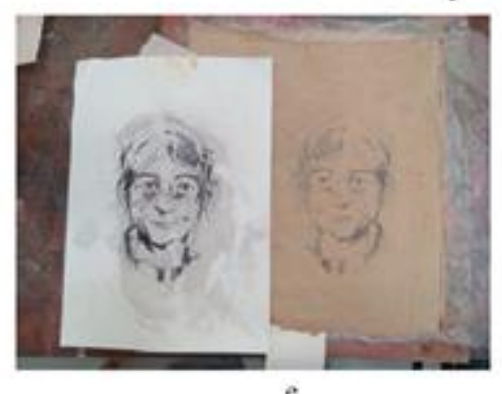

Fig .5: Medium and Matrix

There are various marks left on the papers, some are compatible with medium and some are not. The result was documented and classified according to versatility of leaving marks. Fig 6 presents the data collected from the experiment. (WB. G (1)) on fig 6.a exhibit the medium is mild versatile to the papers. The pigment was sodden when it was hand-pulled. 
Thus, it has a misty image. Fig 6.b shows (WB. W (2)) pigment fades after it was printed multiple times on (W001) and (W002). The images are not consistent unlike (WB. G (1)) the image becomes deform each time. Fig 6.c indicates (WB. S (3 has moderate rate of compatibility with (W001) but a chuck of the fibred caught on the matrix surface. Fig 6.d exhibit (WB. P (4)) has a versatile leaving marks on (NW001). The image has definitely appeared with other papers. (WB. I (5)) was also tested with (NW001) but the image was hazy as shown in fig 6.e. The ink vanishes when it dries leaving the clay marks only.

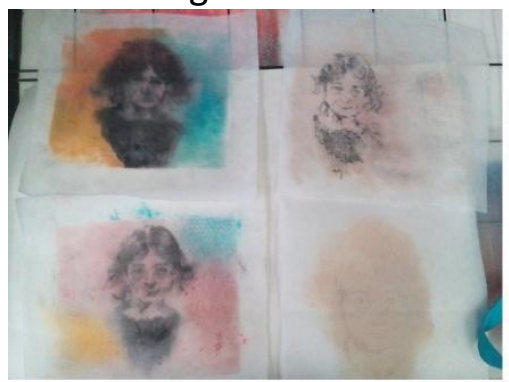

a

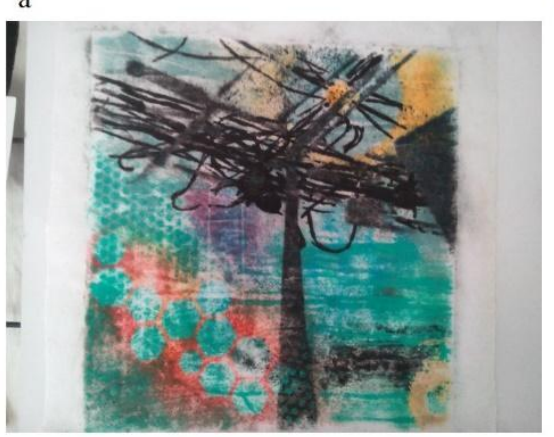

d

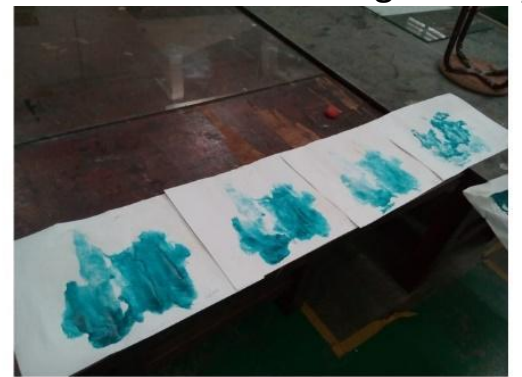

b

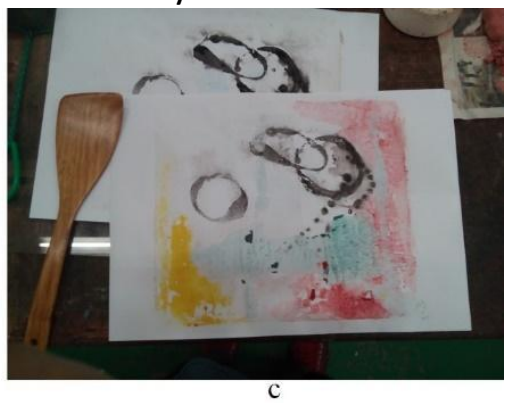

Figure 6: Results from experiments

\section{Result and Conclusion}

The table below shows the data collected from the experiment. It concludes (NWO0) and (NW002) are versatile with the most water-based mediums than woven paper. This shows non-woven paper is suitable for clay print and also supports the electrostatic theory [6], the non-woven paper has greater electric build charge than woven paper. Material such as Pellon and felt are ideal for conducting this experiment.

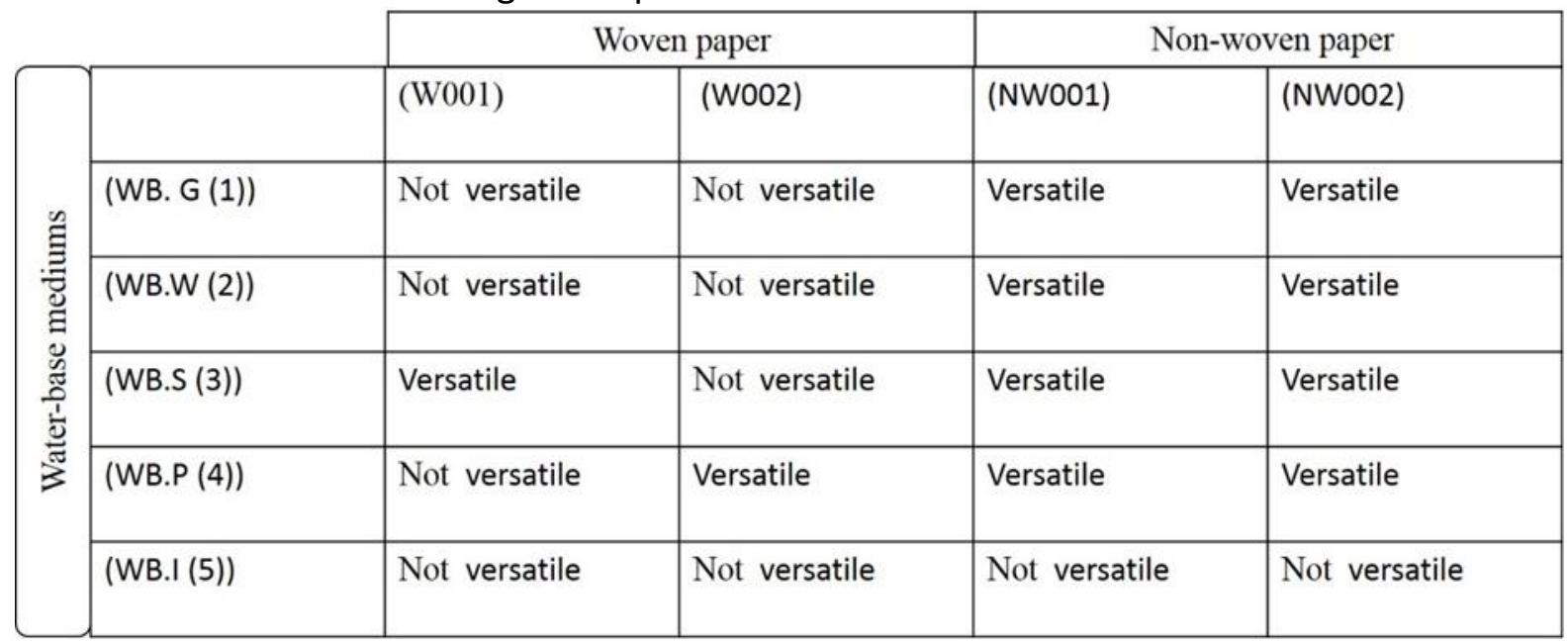

Table 1: Data collection 

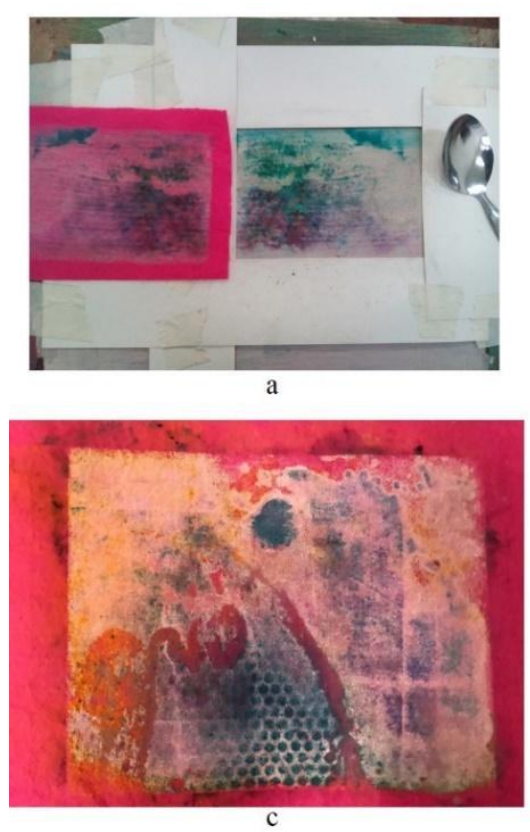
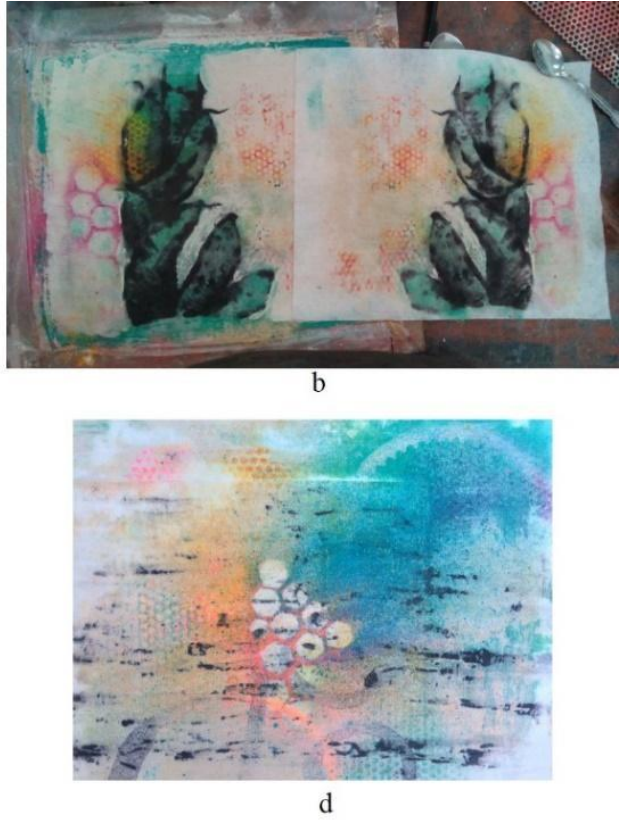

Figure 7 : Non- Woven paper versatile

Figure 7 exhibits samples from the non-woven papers. 7.a \& 7.c, are (NW002) and 7.b \& 7.c, are (NW001). The image is much clearer than the others displayed on woven papers and also, they can pick the image on the matrix without damaging the fibres, unlike the woven papers.

The project was inspired by a cross-disciplinary ceramist who had the desire to cross the gaps. Clay printing has never been done in Malaysia. This type of printing is special, it could be modified to the matrix system and also retain the essence of the earth. It was tested to see how versatile the matrix leaving marks on different types of paper. What follows next is several experiments performed to obtain data on how compatible the relationship between the medium and the surface is. Non-woven papers are seen to be used on the qualifying surface for this specific print form, while woven papers are not used. By replicating Lyon's framework of clay matrix the creative practice - based can do research by recording into work and compilation. This research will be continued in the future to be reviewed by printmakers and educators for eligibility of reassurance for clay print to adapt and utilize in Malaysia.

\section{Acknowledgements}

We are proud to record our highest gratitude to all involved, either directly or indirectly throughout the process of completing this paper. Finally, may we benefit from the blessing of the Almighty and continue to gain happiness in the world and hereafter.

\section{References}

Ary, A. (2018). Using the TASC Model to Develop Gifted Students' Creativity: Analytical Review. Journal for the Education of Gifted Young Scientists, 6 (3), 11-29.

Blais, P. (producer and host of The Potters Cast). (2017, June 05), Printing With Clay: Mitch Lyons: Episode 324 [Audio podcast]. URL: http://thepotterscast.com/324 
Dictionary, O. (2016). Matrix Meaning in the Cambridge English Dictionary. http://dictionary.cambridge.org/dictionary/english/occupation [Accessed 21 Feb. 2016].

Fernandez, P. (Options). (2018), 'Lasting Impressions' demystifies the techniques of printmaking, URL : https://www.optionstheedge.com/topic/culture/lastingimpressions-demystifies-techniques-printmaking

Gogh, D. (The Star Online). (2018), Seni Cetakan exhibit recognises Malaysian printmakers through the generations, URL:

https://www.thestar.com.my/lifestyle/culture/2018/09/07/bank-negara-malaysiamuseum-and-art-gallery-exhibition-printmaking-seni-cetakan

Kulbicki, G., \& Grim, R. E. (1959). A new method for thermal dehydration studies of clay minerals. Mineralogical Magazine and Journal of the Mineralogical Society, 32 (244), 53-62.

Lucas, J (Live Science Contributor), (2015) What Is Static Electricity?, URL: https://www.livescience.com/51656-static-electricity.html

Melot, M. (1988). The Nature and Role of the Print. Prints: History of an Art, 8-131.

Open College of the Arts. (2016) printmaking 1: Introduction of printmaking, United Kingdom, Michael Young Arts Centre n.p.

Planographic printing, (2020). In Wikipedia. Retrieved from https://en.wikipedia.org/wiki/Planographic_printing\#: :text=Planographic\%20printing \%20means\%20printing\%20from,will\%20not\%20mix\%20with\%20oil

Sill, W. R., \& Klein, J. D. (1981) The electrical properties of clay ( No report : 81-989), University of Utah.

USGS. Mineral Commodity Summaries. (2015). United States Geological Service: San Antonio, TX, USA, 2015

Weaver, C. E. (1989). Clays, Muds, and Shales. Amsterdam: Elsevier, 819 pp. 